\title{
Congenital mirror movements
}

\author{
G D SCHOTT AND MARIA A W YKE \\ From the National Hospitals for Nervous Diseases, Queen Square and Maida Vale, London
}

SUMMARY In this report are described seven patients assessed clinically and neuropsychologically in whom mirror movements affecting predominantly the hands occurred as a congenital disorder. These mirror movements, representing a specific type of abnormal synkinesia, may arise as a hereditary condition, in the presence of a recognisable underlying neurological abnormality, and sporadically, and the seven patients provide more or less satisfactory examples of each of these three groups. Despite the apparent uniformity of the disorder, the heterogeneity and variability may be marked, examples in some of our patients including the pronounced increase in tone that developed with arm movement, and the capacity for modulation of the associated movement by alteration of neck position and bio-feedback. Various possible mechanisms are considered; these include impaired cerebral inhibition of unwanted movements, and functioning of abnormal motor pathways. Emphasis has been placed on the putative role of the direct, crossed corticomotoneurone pathways and on the unilateral and bilateral cerebral events that precede movement.

Of the many forms of associated movements, mirror movements are those characterised by involuntary movements executed by one side of the body which are mirror reversals with respect to the intended movements. The term "mirror movement" appears first to have been used by Bauman, ${ }^{1}$ probably being derived from an analogy with mirror writing. ${ }^{2} 3$ Certain mirror movements such as smiling and blinking are obvious in everyday life; they are also features of normal childhood motor function, as seen in the symmetrical Moro response and in the posturing of the arms that can be observed in children at around the fifth month of life. ${ }^{4}$

From the various types of pathological mirror movements, a particular group can be delineated which has the following characteristics: predominant or exclusive involvement of the hands, partial suppressibility, increase in the associated movement with effort, and lack of progression after childhood. We have classified this condition of obligatory bimanual associated movements into three groups: (1) that occurring as a hereditary disorder, usually with an autosomal dominant pattern of inheritance, (2) that occurring in the

Address for reprint requests: Dr GD Schott, The National Hospital for Nervous Diseases, Queen Square, London WC1N 3BG.

Accepted 18 May 1981 presence of a neurological disorder-either congenital or acquired, and (3) that occurring sporadically in otherwise normal individuals. ${ }^{5}$ In this paper, we wish to confine our observations to patients whose mirror movements date from early childhood and in whom therefore the phenomenon appears to be congenital.

In 1977, we observed a 15-year-old otherwise healthy boy, who had throughout life shown involuntary mirror movements of the limbs. At that time it appeared that the movements he executed were similar to the apparently uniform descriptions of previous cases reported in the literature. Since then, we have been able to study six further patients who represent more or less satisfactory examples from each of the three groups referred to above. The purpose of the present report, in which these patients are presented together with a resumé of our earlier case, is to draw attention to the hitherto unrecognised heterogeneity of the clinical features and to consider afresh possible mechanisms that may subserve these rare bimanual synkinesias.

\section{Patients and methods}

The case histories of the patients are given below, and summarised in tables 1 and 2. Patients were investi- 
Table 1 Summary of clinical features

\begin{tabular}{|c|c|c|c|c|}
\hline Case & $\operatorname{Sex}$ & Age $(y r)$ & Condition & Investigations \\
\hline & & & & GROUP 1-Familial \\
\hline \multirow[t]{2}{*}{$1 \mathbf{J G}$} & $\mathbf{M}$ & 39 & ? Recessive inheritance & Normal \\
\hline & & & & GROUP 2-Congenital underlying disorder \\
\hline $2 \mathbf{D H}$ & $\mathbf{M}$ & 41 & Agenesis of corpus callosum & CT scan-features of agenesis of corpus callosum \\
\hline $3 \mathbf{C W}$ & $\mathbf{F}$ & 34 & Klippel-Feil syndrome & $\begin{array}{l}\text { Radiographs-large foramen magnum, blocks of fused cervical } \\
\text { vertebrae; myelogram-wide cervical canal, posterior arachnoid } \\
\text { pouches }\end{array}$ \\
\hline 4 SA & $\mathbf{F}$ & 31 & Usher's syndrome & $\begin{array}{l}\text { Abnormal electro-oculogram and electro-retinogram; audiogram } \\
\text { - severe sensorineural deafness and loudness recruitment }\end{array}$ \\
\hline 5 SK & $\mathbf{F}$ & 17 & Unidentified cranio-cervical anomaly & $\begin{array}{l}\text { Radiographs-spina bifida occulta of } \mathrm{C1} \text {, fused neural arches of } \\
\mathrm{C} 1 \text { and } 2 \text {, fused bodies of } \mathrm{C5} \text { and } 6 \text {. (Normal myelogram) }\end{array}$ \\
\hline \multirow[t]{2}{*}{6 LE } & $\mathbf{F}$ & 30 & $\begin{array}{l}\text { Multiple cervical and thoracic } \\
\text { spinal anomalies }\end{array}$ & $\begin{array}{l}\text { Radiographs-malformed bodies and arches of C6 and 7, arches } \\
\text { of D2-5, and right 3rd and 6th and left } 2 \text { nd, 3rd and 4th ribs }\end{array}$ \\
\hline & & & & GROUP 3-Sporadic \\
\hline
\end{tabular}

Table 2 Mirror movements

\begin{tabular}{|c|c|c|c|c|c|}
\hline Case & Involvement & Amplitude & $\begin{array}{l}\text { Mirror movements } \\
\text { on passive movement }\end{array}$ & $\begin{array}{l}\text { Alteration } \\
\text { in tone }\end{array}$ & Other features \\
\hline $1 \mathrm{JG}$ & hands ++ arms + & $\mathbf{L}=\mathbf{R}$ & - & +++ & Partially suppressible with bio-feedback \\
\hline $2 \mathrm{DH}$ & $\begin{array}{l}\text { hands }++ \text { arms }+ \\
\text { eyes }+ \text { mouth }+\end{array}$ & $\mathbf{L}>\mathbf{R}$ & - & - & \\
\hline $3 \mathbf{C W}$ & hands ++ arms + & $\mathbf{R}>\mathbf{L}$ & - & - & Movements influenced by neck position \\
\hline 4 SA & $\begin{array}{l}\text { hands }+ \text { + arms }+ \\
\text { eyes }+\end{array}$ & $\mathbf{L}=\mathbf{R}$ & - & - & \\
\hline 5 SK & hands ++ toes \pm & $\mathbf{R}>\mathbf{L}$ & - & - & Clumsy right hand \\
\hline $6 \mathrm{LE}$ & $\begin{array}{l}\text { hands }++ \text { eyes }+ \\
\text { toes }+\end{array}$ & $\mathbf{L}=\mathbf{R}$ & - & ++ & Partially suppressible with bio-feedback \\
\hline 7 DC & $\begin{array}{l}\text { hands }++ \text { arms }+ \\
\text { legs }+ \text { toes }+\end{array}$ & $\mathbf{R}>\mathbf{L}$ & + & - & \\
\hline
\end{tabular}

gated with radiographs of the skull and spine, compuited tomography (CT) of the head, electroencephalography (EEG), and spinal and cortical sensory evoked potentials ${ }^{6}$ recorded over the ipsilateral and contralateral scalp. The last two investigations were normal in all patients; abnormalities de'tected and the results of additional abnormal investigations are included in table 1. The patients were also given a neuropsychological evaluation which included a handedness questionnaire, ${ }^{7}$ tests of intelligence (WAIS), and tests of motor proficiency (cutting with scissors, maze tracing, placing coins and matchsticks in a box, and drawing lines) taken from the Oseretsky Scale; 8 psychomotor skills were evaluated using tests of rapidity of movements ${ }^{9}$ and the Perdue Dexterity Test. ${ }^{10}$ The results are summarised in table 3 .

In assessing the movements, each hand was tested independently and observations made concerning the direction of the associated movement (that is mirror or homologous, see reference 5). Most of the associated movements were mirror forms of the intended movements, but at times they were less easy to characterise-as indicated in the case histories below. When writing simultaneously with both hands, four patients produced occasional and fragmentary mirror
Table 3 Neuropsychological Assessment

\begin{tabular}{|c|c|c|c|}
\hline Case & Handedness & $\begin{array}{l}\text { Full scale } \\
\text { IQ (WAIS) }\end{array}$ & Psychomotor performance \\
\hline $\begin{array}{l}1 \mathrm{JG} \\
2 \mathrm{DH}\end{array}$ & $\begin{array}{l}\text { Right } \\
\text { Predominantly } \\
\text { right }\end{array}$ & $\begin{array}{r}131 \\
72\end{array}$ & $\begin{array}{l}\text { Normal } \\
\text { Low normal }\end{array}$ \\
\hline $\begin{array}{l}3 \mathrm{CW} \\
4 \mathrm{SA} \\
5 \mathrm{SK} \\
6 \mathrm{LE} \\
7 \mathrm{DC}\end{array}$ & $\begin{array}{l}\text { Right } \\
\text { Right } \\
\text { Left } \\
\text { Right } \\
\text { Left }\end{array}$ & $\begin{array}{r}102 \\
48 \\
75 \\
114 \\
83\end{array}$ & $\begin{array}{l}\text { Normal } \\
\text { Clumsy and slow } \\
\text { Clumsy and slow } \\
\text { Normal } \\
\text { Normal }\end{array}$ \\
\hline
\end{tabular}

writing, but no definite mirror writing could be seen when writing with the preferred hand alone. The patients were also asked to perform "complementary" bimanual movements, that is tasks which required the simultaneous use of the two hands, as in winding thread onto a spool and threading a nut onto a bolt. In no patient was any associated or interfering movement noted.

Two patients (JG and LE) attempted to control the involuntary movements using bio-feedback. The technique employed EMG feedback from the extensor muscles of the forearm showing the associated movement; feedback was both auditory using a tone of 
varying pitch and visual using a calibrated meter. These patients were able to suppress the involuntary movements for a few minutes after continuous training for periods lasting up to 20 minutes. One patient (JG) was able to control the involuntary movements of both the left and right hands; the other (LE) could only control the movements of the preferred hand. Additional investigations were carried out on patient DH (agenesis of the corpus callosum) in order to assess possible impairment of inter-hemispheric transfer of information. ${ }^{11}$ The assessment disclosed no such impairment; for instance, with eyes closed, objects actively explored with one hand could be recognised by the other.

\section{Case histories}

Case $1, J G$

This 39-year-old consultant for an electronics firm first recalled "clumsiness" of the hands when playing with mechanical toys as a child. He was aware of having difficulty carrying out intricate manoeuvres and his fingers appeared to move clumsily. By the age of 8 years he recalled that his two hands involuntarily tended to move simultaneously. At the age of 14 years he started to learn to play the piano, and whilst his problems probably did not progress, they became more obtrusive and the bimanual movements seriously interfered with this activity. As he became older, he became aware that many or most of the movements performed with one hand were faithfully copied in mirror fashion by the otherfor example, putting his hand in his pocket, writing and turning knobs. Finger and wrist movements were mainly affected with slight involvement of the forearms. Other than an inability to play the piano, there had been no interference with everyday activities including sport. The amplitude of the movements may have increased during childhood and were enhanced by stress and anxiety, but he had always partly been able to suppress the unwanted activity, albeit with effort, and this appeared to impose a "strain" on both arms. It is possible that he involuntarily used this increase in tone in an attempt to control the mirrored movements. The face and legs were uninvolved.

He learnt to write at around the age of 4 years, talked well at 3 and walked at 18 months. His general health remained excellent. His only sibling, a brother, also exhibited mirror movements although unfortunately details remain anecdotal since he died aged 27 years in an accident. Throughout life he had had difficulty in manipulating fine objects on account of "stiffness" and "clumsiness" of the fingers, and he showed non-progressive but very marked mirror movements affecting both hands. His parents and other relatives were unaffected and there was no consanguinity.

Examination of JG showed slight synkinetic movement upwards of the ipsilateral corner of the mouth on closing each eye; on voluntarily closing each eye, particularly the left, some associated closure movements of the other eye also occurred. There was neither motor nor sensory deficit in the limbs, the reflexes were normal, and tone at rest, co-ordination and fine and discrete finger movements were also normal. On movements of one arm, however, and even even on anticipation of movement, striking increase in tone in the opposite arm appeared, this hypertonicity appearing poorly localised in the opposite limb. Discrete movements of the fingers of either hand produced mirror movements of the contralateral fingers, whether the movements were made individually or in combination in more complex tasks such as writing and manipulating fine objects. Mirroring also occurred on movement of the hand and wrist, and to a small extent on movement of the forearm and even upper arm. The mirror movement was often less in amplitude than the intended one, and could be partially suppressed, usually being associated with further increase in tone. All synkinetic movements were enhanced when the intended movement was carried out with effort. There was no noticeable asymmetry between the two sides, passive movements did not cause mirroring, and there was no abnormality of the legs.

Case 2, DH

This 41-year-old waiter had three brief epileptic seizures, and at that time mirror movements first attracted medical attention. Enquiry, however, revealed that the patient had had mirror movements for as long as he could recall. As a child he remembered his mother encouraging him to sit on one hand to stop the other hand moving. He was almost illiterate, and had little recollection of making mirror movements when trying to write. Everyday tasks proved difficult on account of these movements: for instance lifting a teapot with one hand resulted in the other hand becoming lifted up and making gripping movements. Similar problems occurred holding jugs and beer mugs -a source of embarrassment in his occupation. Combing his hair resulted in similar movements of the other arm, also when he manipulated nuts and bolts and used a screwdriver. These fine, gripping and turning movements had been the most troublesome, especially when effort was required, whilst no problems had been encountered with grosser movements such as hammering; he had been unable to control his symptoms voluntarily. There was a greater tendency for mirroring to occur in the left hand with intended movements of the right, than vice versa. There had been no progression and his legs and face were uninvolved. His previous and family history were unremarkable.

Examination was normal except for the presence of mirror movements. These affected individual finger movements - such as flexion and extensionand also more complex movements such as serial opposition of the thumb to each finger. There were some mirror movements on opening and closing the fist, also seen with aotivities such as doing up buttons, turning knobs and winding a watch. On forceful 
movement against resistance, mirror movements affecting shoulder abduction and adduction and also elbow flexion and extension could be demonstrated; similar mirror movements could be brought out with gross arm movements, for instance when inscribing circles in the air with the outstretched arm or even with the hand alone. When drawing in rungs of a ladder in a centrifugal direction, there resulted some slight mirror movements of the contralateral hand, and with attempts at writing with either hand, some low amplitude involuntary movements were visible in the contralateral hand. There was some asymmetry of response, the right hand tending to mirror those movements made with the left hand to a lesser extent compared with when the right hand made the intended movement. In the face, whilst closure of the right eye caused associated closure of the left eye, only slight associated movements of the right eye occurred when closing the left. Elevation of the left corner of the mouth caused some elevation of the right side, whilst vice versa, more synkinetic movements occurred. The feet were unaffected. Tone remained normal throughout testing and passive movements did not cause synkinetic movements.

\section{Case 3, CW}

This 34-year-old lady was born with a short neck but remained asymptomatic until the age of 23 years. She then complained of episodes of tingling in the left arm and leg, intermittent burning in the left arm and slight impairment of grip of the left hand. Her family history was unremarkable. The findings on examination were similar to those currently observed. Although not having sought medical attention for this, mirror movements had been present for as long as she could remember, and according to her mother had been present even during infancy. Thus when she had reached for an object with one hand, the other hand would make a similar movement. The patient remembered as a child mirror movements occurring, for instance when she did up buttons or turned knobs; in one instance, she recalled that when scratching the side of her head with one hand, the other produced a curious partial mirrored movement. When aged 10 years, she tried to suppress the unwanted movement, although suppression caused considerable and rather diffuse "strain" in the arm showing the mirror movements. Over the years, she had unconsciously partly been able to control the movements, although certain activities she still finds difficult-for instance plaiting her child's hair which involves different but simultaneous activity of the two hands. Activities involving co-operative bimanual movements - such as sewing or manipulating nuts and bolts, cause no difficulties. Affected movements are mainly those of the fingers and wrist; over the years, control has been executed predominantly over the thumb, index and middle fingers, and mirroring in everyday life now particularly affects the little and ring fingers. There is no asymmetry. Movements requiring effort such as undoing tight bottle tops or taps cause enhanced mirroring, and also a sense of diffuse strain mainly in the forearm muscles, as referred to above. Forearm mirror movements particularly occur when she stirs a cooking pot. Certain activities have proven more difficult: when writing she has developed the habit of making a fist with the left hand to prevent the unwanted movements. Some larger movements of the arm also tend to cause mirroring-for instance catching a ball. Learning to play the piano had to be abandoned due to the considerable difficulties encountered, and as a nurse, she tended to drop a vial held in one hand, when the other hand was drawing-up fluid into a syringe.

Examination revealed a very short neck with low hair line, cervical kyphosis, restriction of all neck movements to about 15 degrees, and webbing at the shoulders. There was first degree horizontal nystagmus in both eyes on lateral gaze in either direction; in the left arm, there was slight weakness affecting left shoulder abduction and elbow, wrist and finger extension. The arm reflexes were reduced bilaterally. There was neither sensory loss nor ataxia, and no signs of a foramen magnum lesion or spinal cord involvement. There were obvious mirror movements of the fingers with particular involvement of the little and ring fingers. The movements were not always precisely mirrored and symmetrical: particularly noticeable was that movement of a finger of the right hand tended to produce some diffuse synkinetic movements affecting at times several fingers of the left hand. Mirroring affected wrist movements, and also to a slight extent more gross movements of the whole arm-such as when making circles in the air with the outstretched arm. Usually the amplitude of mirroring produced by the right hand was greater than that of the left. A striking finding was the increase and slowing of the mirror movements with forward flexion of the neck, at a time when there was no other demonstrable change in neurological function. Synkinetic movements of the face and legs were not seen.

\section{Case 4, SA}

This 31-year-old lady, the product of a pregnancy complicated by antepartum haemorrhage, was born uneventfully weighing $5 \mathrm{lb} 10 \mathrm{oz}$. Whilst the perinatal period was unremarkable, her developmental milestones were markedly delayed. She crawled at 9 months, walked at 2 years, and was slow to talk: her speech was almost unintelligible by the age of 5 . At 7 years she was noted to be deaf, and at 8 to be partially sighted and bilateral cataracts were found. She had three grand mal seizures between the ages of 5 and 23 years. She had never been able to read or write and had attended special schools; for a time she managed a simple assembly job in a factory. Her family history was unremarkable and there was no parental consanguinity. Througout the patient's life, her mother had been aware of the presence of mirror movements affecting the arms. The patient herself was able to recall few details of these movements 
although she did remember their occurrence when she turned knobs on a radio; the movements had not been progressive and caused no disability.

On examination of this retarded girl, her visual acuity was $6 / 60$ in the right eye and $6 / 36$ in the left, and there was tunnel vision, attenuated fundal vessels, retinal pigment epithelial degeneration and cataracts in both eyes. There was severe bilateral deafness. In the limbs there was neither weakness nor alteration in tone but slowness in executing fine finger and toe movements bilaterally. There was no ataxia. Sensation was normal, as were the tendon reflexes, and the plantar responses were flexor. A diagnosis of Usher's syndrome ${ }^{12} 13$ had been made. The face showed no abnormal associated movements, except that she was unable to close either eye independently. Mirror movements were evident in the upper limbs and especially the hands, and were particularly striking on lateral finger movements and when more complicated tasks were undertaken such as sequential opposition of the thumb to each finger. There was a tendency for spread of discrete finger movements to involve adjacent fingers-for example, flexion of an index finger often caused flexion of the adjacent thumb as well as mirror movements of both these fingers of the opposite hand. Attempts at writing produced some synkinetic movements of the fingers of the left hand. Slight mirroring also occurred proximally, particularly in the forearms when rotational movements were made. The legs were uninvolved. There was no alteration in tone on executing arm movements nor with change in posture of the head.

Case 5, SK

This 17-year-old girl had had weak and clumsy hands since birth; there had been a suggestion of progression in recent years, probably attributable to increasing awareness as she started employment. The symptoms had always predominantly affected the right arm, which she found difficult to elevate, and marked impairment in function of the right hand resulted in almost exclusive use of the left. She had noticed longstanding difficulty in carrying out fine tasks such as writing, typing and in doing up and undoing buttons. Born in India, she came to England at the age of 5 years, started school a year later and after leaving at the age of 16 , she took up work as a shop assistant. Her family history was unremarkable. She had been aware of mirror movements throughout life, although they caused her no concern. She had noticed some asymmetry, with a greater tendency when using the left hand for the right hand to imitate movements than vice versa.

Examination of this left handed girl revealed three café-au-lait patches on the skin, and a small midline pit in the back of the neck; the latter had apparently been noted at birth. The cranial nerves were normal. There was slight thinning of the muscles of the shoulder girdle and small muscles of the hands, clawing of the fingers bilaterally but particularly the right, winging of the scapulae, and bilateral but particularly right sided weakness of both deltoids and spinati, triceps, wrist and finger extensors and the small muscles of the hands. Movements of the hands were carried out slowly but there was neither ataxia nor disturbance of tone. The legs were normal. Whilst the biceps and brachioradialis reflexes were well preserved, the triceps and leg reflexes were sluggish; the abdominal responses were absent but the plantar responses flexor. Sensory testing revealed slightly impaired postural sense in the fingers bilaterally. Mirror movements were also apparent. Active use of the left hand produced mirror movements of the right; thus tapping with a single finger, abduction of the fingers, and pill-rolling movements of the fingers as well as gripping, pronation and supination of the wrist, and more complex tasks such as undoing tops and turning knobs all produced symmetrical movements of the right side. Attempting these movements with the right hand produced less mirror movements of the left, and movements executed with the right hand frequently showed diffuse dispersal of the mirror movements produced by the left hand. She had difficulty holding a pen, but writing with the left hand produced marked mirror movements of the right. Mirroring was not detected proximally in the upper arms but there was a suggestion of occasional, slight and variable toe movements of the contralateral great and second toes when rapid flexion-extension movements of the toes of one foot were performed.

\section{Case 6, LE}

This 30-year-old-lady was born with a mis-shapen and shorter left foot and leg. This had caused little functional disability but she had come under medical care as a result of some local pain in that foot. Her family history was negative. Her parents had noted mirror movements since her birth, and as a young child, she recalled that when waving to people in the street the other hand would make similar but less marked movements. As she learnt to write, she became aware of mirror movements of the left hand, and in particular releasing the grip of one hand caused similar release movements of the other. Numerous activities were associated with mirror movements, including turning door knobs, sewing, using a screwdriver and catching a ball. These movements resulted in embarrassment rather than functional disability.

Examination revealed slight weakness of neck flexion, elevation of the right shoulder, flattening of the interscapular region, thoracic scoliosis and marked pes cavus deformity of the left foot. There was slight weakness of all movements of the left hand and arm, which although causing no functional impairment, she had been aware of throughout life. There was severe weakness of left ankle dorsiflexion and eversion and also toe dorsiflexion. Sensory examination was normal. The arm reflexes were normal and symmetrical, whilst the reflexes in the left leg were exaggerated, the left plantar response was extensor and the left sided abdominal responses were reduced. 
Mirror movements were evident, and affected discrete and fine finger movements of both hands, opposition movements of the thumb to each finger, and abduction and adduction movements of the fingers. The upper arms were not affected. When either arm was used, marked increase in tone occurred in the contralateral arm, but this was not so striking as in JG. There was no significant asymmetry. In the face, right eye closure was associated with involuntary closure of the left eye, whilst left eye closure was accompanied by only slight mirror movements of the right. There were some mirror movements of the toes of the right foot on flexion of the left toes. Passive movements did not produce any mirror phenomena.

Case 7, DC (Resumé from Schott and Wyke ${ }^{5}$ )

This 15-year-old boy had had involuntary mirror movements since infancy, his parents noticing that at the age of 3 years, picking up objects with one hand was associated with similar movements of the other. By the age of 7 years these movements were more prominent and particularly affected gripping; the movements could only be suppressed partially and were increased with effort. He found holding milk bottles in both hands was hazardous, since release of one bottle caused release of the other, and later rope climbing, typewriting and piano playing had to be abandoned. The mirrored movements when writing caused considerable embarrassment at school. There had been no progression over the years and medical advice was only sought because difficulty was anticipated in the boy's aspirations to become a diamond cutter. The family history was unremarkable.

Examination was normal except for the presence of mirror movements, which spared the face. Individual finger movements and more complex movements of the hands produced mirror movements of the contralateral side, although the mirrored movements were more evident when the left hand was carrying out voluntary movements. Less mirroring occurred on more proximal movements of the arms. Passive movements of the fingers and wrist, and pronation and supination of the forearm, especially when abruptly executed, sometimes produced similar though small amplitude mirror movements. In the legs, slight mirror movements were detected on voluntary movement of the toes or ankle. All associated movements were enhanced when active movement was performed against resistance.

\section{Discussion}

Although the term "mirror movements" is employed to describe those involuntary movements executed by one side of the body which are mirror reversals with respect to the intended movements, usage has tended to lead to a less strict application of the meaning of the term, and in many instances it is used to imply simultaneous and often bimanual movements which are not necessarily strictly mirrored. Imitative, homologous, and corresponding are alternative and less restrictive terms sometimes used. ${ }^{14}$ That this aspect is not merely semantic becomes evident when considering that different mechanisms may have to be invoked when considering explanations for these movements.

Interest in associated movements in general first developed during the 19th century (for historical review, see reference 14 ), but a century ago, Westphal ${ }^{15}$ delineated symmetrical synkinetic movements as a specific group amongst these involuntary movements. The normal mirror movements of children and adults have been referred to earlier, but pathological mirror movements particularly affecting the hands are also seen both in children $^{16}$ and in adults in many acquired disorders of the nervous system, including cerebrovascular accidents, ${ }^{17}$ cerebral tumours, ${ }^{18} 19$ trauma, ${ }^{2021}$ extrapyramidal disease ${ }^{22} 23$ and subarachnoid haemorrhage. ${ }^{24}$ In this report, however, we have confined ourselves to a consideration of some unusual patients whose bimanual mirror movements are congenital, and in some of whom an underlying and relevant abnormality of the nervous system has been detected.

Despite different underlying disorders, the seven cases described here share the characteristic features that have long been recognised in this condition: the movements affect solely or predominantly the hands and especially the fingers, are present on active and rarely passive movements of one side, are noted during infancy and show no significant progression, and are themselves associated with no other functional deficit unless an underlying neurological disorder should contribute additional handicaps. Often the mirror movement is of a lesser amplitude than the intended one, and there is no doubt that some degree of voluntary control can be exerted over the associated movement. These associated movements may often be only a fragment of the voluntary movement and sometimes do not even resemble it; this explains for instance why when writing, mirror writing is not inevitably produced by the non-dominant hand, and also demonstrates the lack of precision of the term "mirror movements" when applied to these patients.

The functional problems these movements cause are usually insignificant; curiously, typewriting and playing the piano are often impossible, ${ }^{25}$ whereas sewing, manipulating nuts and bolts, and other fine mechanical tasks appear to present few difficulties. It may be that this is because activities 
such as piano playing demand independent and separate activity of the two hands, whilst many of the other tasks require independent yet bimanually co-ordinated activity. Other curious and predictable problems have been noted-in one of our patients (Case 7) difficulties were encountered when carrying bottles of milk in each hand, and the problems encountered by the sailor attempting to climb a rope can easily be envisaged. ${ }^{26}$ It is noteworthy that only one of the seven cases described here came to medical attention on account of these movements, which demonstrates the lack of both progression and of the development of further neurological problems.

Mirror movements have been investigated by electromyographic (EMG) techniques for many years, ${ }^{27-30}$ but detailed reports of patients with congenital mirror movements studied by current EMG techniques are sparse. Regli, Filippa and Wiesendanger ${ }^{31}$ analysed mirror movements in two brothers: EMG investigation of rapid flexion movement of the forearm revealed activity in the contralateral arm with coactivation of the antagonistic muscle pair. Whilst the latency of the activity was often the same on the two sides, on average the latency of the mirror activity was slightly longer, and Jelasic and Ott $^{19}$ reached similar conclusions studying patients with mirror movements who were otherwise normal. Baird, Robinson and Buckler ${ }^{32}$ studied mirror movements electromyographically in patients with the KlippelFeil syndrome; although the association between the syndrome and mirror movements was highly significant, the presence of mirror movements could not be correlated with any clinical or radiological features. Notermans, Go and Boonstra ${ }^{33}$ have also studied mirror movements using EMG in a patient with the Klippel-Feil syndrome. Whilst of interest, these reports have contributed relatively little to an understanding of underlying mechanisms, and when EMG studies were undertaken on our patient DC, we were impressed by the great variability of the response evoked in the contralateral muscles.

Despite the apparent uniformity of the clinical features, our cases demonstrate a heterogeneity barely recognised in the literature on the subject. For instance, there was often asymmetry between the movements of the two sides, in two of our cases there was very pronounced increase in tone when the mirror movements were produced, in three cases slight associated movements of the toes could be observed, in one patient the movements were markedly affected by head posture, in another passive movements induced mirror movements, and in four patients some associated movements of the eyelids or mouth were noted. The latter as with many other associated facial movements $^{34}$ are commonly found in otherwise normal individuals and likely to be of little significance. As well as the various differences in the clinical features, the underlying conditions in some patients include a number of more or less identifiable disorders, an aspect which needs to be accounted for when attempting to construct any unifying hypothesis to explain these abnormal movements.

CONSIDERATIONS OF UNDERLYING ABNORMALITIES Abnormalities of the cervical spine

The commonest condition recorded in association with congenital mirror movements has been the Klippel-Feil syndrome, in which numerous associated developmental defects such as Sprengel's deformity, platybasia, and extradural spinal masses may occur, as also may defects of the cervical and thoracic cord. ${ }^{35}$ Mirror movements were first noted in this congenital cervical spine abnormality by Bauman, ${ }^{1}$ who reported on their occurrence in four out of six cases, and although the association has been questioned, ${ }^{36}$ several other confirmatory reports have subsequently appeared (see reference 37). Mirror movements have also been described in other congenital skeletal abnormalities of the craniocervical region, such as the Arnold-Chiari malformation and basilar impression. ${ }^{38}$ The propensity for mirror movements to occur in these conditions is unexplained. Of considerable importance are the pathological studies in two cases of the Klippel-Feil syndrome associated with mirror movements in which striking abnormalities of the cervical cord have been demonstrated. In the case described by Gunderson and Solitare, ${ }^{39}$ apart from the apparent absence of pyramidal decussation with defects of cord fusion, the corpus callosum was found to be abnormally thin. In Avery and Rentfro's ${ }^{40}$ case, there was nearly complete division posteriorly of the cervical and upper thoracic cord, but unfortunately the brain was not examined.

A possible mechanism that has been considered by many of these authors is that of impaired decussation of the pyramidal tracts, perhaps with consequent use of alternative, less specific and bilateral pathways. In the present report, two patients had unequivocal major skeletal abnormalities of the cervical and upper thoracic spine with a probable abnormality of the underlying cord, and a further patient had clinical evidence of a high cervical lesion with a congenital mid- 
line cutaneous abnormality-the underlying defect remaining unidentified. In some instances, mirror movements may be inherited (see below) and it should be recalled that certain abnormalities in the region of the craniocervical junction may themselves be inherited, including the Klippel-Feil syndrome, ${ }^{41}$ basilar impression ${ }^{42}$ and the ArnoldChiari malformation. ${ }^{43}$

\section{Agenesis of the corpus callosum}

Whether mirror movements take place via interhemispheric pathways has long been debated, but evidence on this is lacking. It is of interest, however, that callosal section does not appear to prevent at least those mirror movements acquired through trauma. ${ }^{44}$ The occurrence of these movements in agenesis of the corpus callosum has attracted little attention even when noted. ${ }^{11}$ Our observation of a patient (Case 2) who presented fortuitously, whose callosal agenesis would have remained undetected without computed tomography and in whom no other neurological abnormalities were encountered, raises the question as to whether previously reported "normal" individuals with mirror movements who were not investigated by such techniques, may have had an undetected abnormality of this kind. The association of the Klippel-Feil syndrome with an abnormally thin corpus callosum has been referred to above. Also pertinent is the agenesis of the corpus callosum detected in one member of a family with mirror movements, mental retardation and various skeletal abnormalities. ${ }^{45}$

Is it possible to link the two groups of patients in whom an underlying defect can be demonstrated, that is those with abnormalities of the corpus callosum and of the cervical spine and cord? Apart from the necropsy findings referred to above, agenesis of the corpus callosum is accompanied by a remarkably high incidence of associated anatomical abnormalities, and particularly striking is the study by Parrish, Roessmann and Levinsohn ${ }^{46}$ in which six of 11 patients with agenesis of the corpus callosum were found to have abnormalities involving the pyramidal system. In their review of the literature, associated pyramidal tract abnormalities were reported in six of 47 other cases, which they considered to be an underestimate. It seems reasonable therefore to suggest that as mirror movements may be associated both with agenesis of the corpus callosum and with congenital cervical spine abnormalities, and as there is a high incidence of abnormalities of the pyramidal tracts in both disorders, abnormalities of these tracts may provide a common basis for the occurrence of mirror movements.

In considering structural aspects, reference should be made to the apparently unrelated combination of mirror movements with hypogonadotropic hypogonadism and anosmia. This triad has recently been reported as a familial disorder by Conrad, Kriebel and Hetzel, ${ }^{37}$ and possible earlier examples cited. These authors proposed that hypogonadism and anosmia (Kallman's syndrome) may arise from a developmental dysraphic stateanalogous to for example the Klippel-Feil syndrome-and thus all the known structural disorders seen with mirror movements appear to share a defect of midline structures, perhaps with attendant abnormalities of neural topography.

\section{Mental retardation}

It is well recognised that the bilateral associated movements which are a normal feature of infancy are more likely to persist in brain damaged children, ${ }^{478}$ and mirror writing is also more commonly encountered among "defective" children. ${ }^{49}$ Non-specific "brain damage" appears to allow mirror movements to persist indefinitely, and this was recognised by von Fragstein ${ }^{50}$ who commented on these movements in "idiots"; the movements have also been described in hereditary mental defectiveness, ${ }^{45}$ hereditary schizophrenia, ${ }^{51}$ and "phenylpyruvic oligophrenia". ${ }^{52}$ In our patient with Usher's syndrome, mirror movements appeared in a setting of multiple congenital defects of which mental retardation was one major manifestation. There has been speculation that the disappearance of normal mirror movements might be related to the development of a hypothetical "inhibitory" mechanism which would allow separate, individual and non-mirror movements to occur. This hypothesis, and the possibility that inhibition may fail to develop in patients with mental retardation and aggression, ${ }^{53}$ are discussed later.

FAMILIAL AND SPORADIC CASES

In these two groups, patients with congenital mirror movements have no detectable abnormality of the nervous system. The inclusion of our case JG as an example of familial mirror movements must remain unsatisfactory, as we were unable to assess the reportedly affected brother. However there seems no reason to doubt that both brothers were similarly affected, and we are aware of 18 reports of familial mirror movements affecting 86 individuals (see reference 37). The usual mode of inheritance is as an autosomal dominant, although Lackner ${ }^{54}$ described a family with a less 
well defined pattern of inheritance, and Rasmussen and Waldenström ${ }^{55}$ reported a patient with mirror movements whose healthy parents were first cousins and where an autosomal recessive mode of inheritance was postulated. It may be, therefore, that there is heterogeneity amongst the familial cases, although inheritance as an autosomal dominant condition is the most common. Of particular interest in our case is the striking hypertonicity developed by the limbs in the presence of mirror movements; whether this characteristic is typical of familial cases is not known, although it was a feature of one of Lackner's ${ }^{54}$ two cases.

The familial incidence of a number of craniocervical abnormalities in which mirror movements may occur has already been referred to, and these abnormalities are usually inherited as autosomal dominant conditions. Agenesis of the corpus callosum may also be inherited, and both autosomal dominant and recessive patterns have been described. ${ }^{58}$ Whether there is a specifically inherited abnormality of motor pathways is unknown; it is of interest, however, that at least in the peripheral nervous system, familial patterns of anomalous innervation have been described, the mode of inheritance again probably being as an autosomal dominant. ${ }^{57}$

Since the first obscure description by Thomayer in 1887,5859 nine patients have been reported in whom mirror movements occurred as a nonfamilial condition in the absence of any identifiable associated neurological or skeletal abnormality. ${ }^{519}$ It should be emphasised that in the majority of these cases which we have termed sporadic, normality was assessed on clinical grounds. The case (Patient 7) described by us and summarised above has been the only one in this group to have been investigated by modern techniques, now a prerequisite for inclusion in the group of otherwise normal in'dividuals.

MECHANISMS OF CONGENITAL BIMANUAL MIRROR MOVEMENTS

All theories which attempt to explain these movements must account for why the movements affect solely or predominantly the hands and fingers, commence during early life and do not progress, and may be partially suppressible. The theories should also account for the fact that although the same bimanual synkinetic movements normally occur in children and then disappear during the first or second decade,,$^{47860}$ they may occasionally be seen on extreme effort in healthy adults, and can be demonstrated in normal people as sub- clinical movements by various techniques, including plethysmography ${ }^{61}$ and EMG. ${ }^{27}{ }^{62}$

\section{Inhibitory mechanisms}

Those early theories concerning inhibition and referred to above envisaged that with normal maturation, an inhibitory centre or mechanism develops which allows individual, separate and non-synkinetic movements to occur. There is some evidence for the presence of such a process. For example, left handers probably naturally write in mirror script from right to left, and it is education and cultural influences which tend to cause conventional script to supersede. ${ }^{83}$ Moreover, inhibition can apparently be overcome in right handers, who when obligatorily taking up writing and other activities with their left hand, may then transiently undertake mirror movements almost unaware. ${ }^{64}$ Thus it seems that inhibitory mechanisms may be continuously active but are capable of being removed.

There are two other aspects relevant to theories of inhibition which require comment. First, concerning movement-related cortical potentials, it has long been recognised that with unilateral hand movement, the first EEG activity prior to movement, the readiness potential or Bereitschaftspotential, is diffuse, bilateral and symmetrical, and the last pre-motor potential to be recorded is restricted to the contralateral hand area of the motor cortex (for references, see 65, 66). The intervening potentials are currently being evaluated, and whilst controversial, ${ }^{62}$ these may include an ipsilateral pre-motion potential ("Pl") which it has been suggested may be related to inhibitory activity of ipsilateral pathways. ${ }^{67}$ Second, information obtained from vascular studies indicates that there is increased blood flow in both supplementary motor areas during the programming and execution of individual finger movements, but increased regional blood flow in only the contralateral primary motor area. ${ }^{68}$ The parallel information from these two different types of study raises the question as to whether some form of inhibition or modulation may be occurring between early bilateral cerebral activity and later contralateral cerebral activity-inhibition which could be abnormal in patients with mirror movements.

Functional considerations also point to the separation between diffuse bilateral and discrete contralateral cerebral activity. In man, at least in respect of the limbs, focal stimulation of the motor cortex results in purely contralateral movements. This is evident in the normal subject 
with stimulation through the intact skull, ${ }^{69}$ in patients with focal motor epilepsy, and at surgery on the exposed cortex ${ }^{70}$ indeed, Penfield and Jasper $^{70}$ state "bilateral representation of movement of either extremity does not exist in man as far as our experience of Rolandic stimulation goes." (Unfortunately information at present is lacking on the effect of percutaneous stimulation of the motor cortex in patients with mirror movements.) These abnormally-induced movements which follow direct stimulation of the motor cortex are, however, clearly different from the normal, programmed and sometimes deliberate movements presumably generated deeply, diffusely and bilaterally and in which the supplementary motor areas become activated; which if either of these mechanisms is pertinent to mirror movements remains unknown.

These aspects leave unanswered why the abnormal movements affect the hands and fingers, usually in the absence of any defect of fine finger control or discrete finger movement. Theories of inhibition also need to explain the heterogeneity, variability, and partial suppressibility of the movements, and the effect of passive movements in inducing contralateral movements. Such passivelyinduced associated movements were present in one of our cases, and have been described in other reports, for instance by Drinkwater ${ }^{71}$ and Guttman, Maclay and Stokes. ${ }^{72}$ Presumably focal afferent impulses trigger contralateral motor pathways but there is no evidence, apart from the questionable $^{73}$ case reported by Drinkwater, ${ }^{71}$ of allocheiria or any other phenomena affecting the sensory system in patients with mirror movements. The effect is presumably linked to localised sensory pathways since only the contralateral part is activated following passive movement; the application of studies on cortical motor potentials following both voluntary and passive finger movements $^{74}$ to patients with mirror movements may prove revealing.

\section{Abnormal pathways}

A second major concept invoked has been that of abnormal descending motor pathways. Abnormalities of the corpus callosum and of pyramidal decussation in the cervical region have been considered above; other theories involving neural topography have also been considered, including inhibition of bilateral cerebral representation. ${ }^{26}$ loss of suppression of bilateral activity, ${ }^{75}$ impaired inhibitory function of the parietal lobe, ${ }^{21} 24$ and use of ipsilaterally projecting corticospinal pathways. ${ }^{313778}$ The case reported by Haerer and
Currier $^{76}$ is of particular importance in this context. A patient with congenital and familial mirror movements sustained a cerebral infarction leading to a right hemiplegia; mirror movements persisted in the hand which otherwise remained completely flaccid and paralysed. It seems unlikely that these movements could be due to activity of the left hand motor cortex and Haerer and Currier postulated that the movements of the right hand arose either from the right (ipsilateral) cortex or distant subcortical structures, and that mirror movements in general might be caused by distribution of cortical motor neurones from each hemisphere to each "cervical cord hand area" in association with incomplete pyramidal decussation. It should be emphasised that the nature of anatomical abnormalities in patients with mirror movements remains virtually unknown. It is difficult, however, to envisage how the variability of the movements could occur in the presence of gross abnormalities or lesions affecting motor pathways, particularly when impairment of motor function rarely occurs. The relation between mirror movements and position of the neck in our patient (case 3 ) is of interest, since it suggests a possible mechanical factor altering the function of motor pathways specifically at that level.

The complexity of the motor pathways needs no emphasis. There is considerable anatomical variation of these pathways in man, ${ }^{77}$ and of particular importance is one of the conclusions reached from Nathan and Smith's ${ }^{78}$ later study: the lateral corticospinal tract of each side has bilateral influences. In the following section, some aspects related to specific corticospinal pathways will be considered.

A hypothesis combining mechanisms of inhibition and abnormal pathways?

A satisfactory explanation for congenital mirror movements may lie in an abnormality affecting the important direct, crossed corticomotoneurone pathways, which-at least in primates-are now firmly established as being fairly specific for movements of the hands and in particular for the execution of fine finger movements. ${ }^{79} 80$ These direct and crossed pathways develop relatively late and coincide with the acquisition of motor skills ${ }^{81}$ -both crucial aspects when explaining congenital mirror movements. In those of our patients whose mirror movements arose in a setting of recognisable abnormalities, a common factor might well comprise an abnormality of these specific pathways. Consistent with the use of the direct corticomotoneurone pathways is neuropsychological 
evidence, which also suggests that abductive movements-probably relevant for fine and individual finger control-are subserved by the contralateral hemisphere and may be mediated by these crossed motor neurones. ${ }^{82}$ An abnormality affecting, for instance, decussation of these pathways in the brain or cervical cord must however remain speculative.

If the direct, crossed corticomotoneurone pathways are implicated in mirror movements, can inhibition of these pathways be demonstrated? It is of interest that our patients were able to undertake everyday activities without difficulty when the two hands were employed together, and similarly we did not observe associated movements in any of our patients when both hands were used co-operatively, which suggests that inhibition may be occurring at least in these circumstances. In this respect the observations made by Jung and Dietz $^{83}$ are of relevance. They found that whilst there was a unilateral prolongation of motor latency in affected muscles of patients with disorders affecting one pyramidal pathway, this delay in initiation of voluntary movements disappeared when movements were made bilaterally. They considered the best explanation was the use of ipsilateral projections of uncrossed pyramidal fibres to the motor neurones. Recalling that the readiness potential and cerebral blood flow in the supplementary motor areas are bilateral, inhibition of these ipsilateral pathways perhaps usually occurs, the inhibition only being removed or circumvented by bilateral movements. There is some further evidence which might support this proposal. Mention has already been made of the controversial movement-related pre-motion potential ("Pl") which is ipsilateral to the voluntarily contracting muscles; of interest is the observation that on bilateral movement of the thumb, Shibasaki and $\mathrm{Kato}^{67}$ could not record this ipsilateral potential, and they suggested that it might indeed be related to inhibition of imitative (mirror) movements.

The relevance of the alteration in tone noted in two of our patients is uncertain. Whilst clinical disorders of the basal ganglia and cerebellum are not typically accompanied by mirror movements, normal movement is preceded by diffuse neuronal activity in cerebellar structures, thalamus, and basal ganglia (for reviews, see references 65 and 84). Whether the striking increase in tone preceding hand movement in our patients is related to activity from these more diffuse extrapyramidal pathways remains unknown, also whether the abnormality of tone results from or is an inherent part of the movement disorder. It could even be that alterations of tone are relevant to the partial suppressibility of the mirror movements, and the influence of mood and relaxation on the fluctuation of discrete movements of the hands in disorders such as writers' cramp will be recalled. In addition, whilst the mode of action of biofeedback remains unclear, the technique has for long been used clinically to inhibit unwanted motor activity; 85 it is of interest that two of our patients very rapidly learnt to diminish their mirrored movements transiently using bio-feedback - which perhaps argues in favour of effects on diffuse possibly subcortical mechanisms.

That a disturbance or anomaly of higher cortical function could play a part in bimanual movements also requires consideration but appears unlikely, ${ }^{86}$ and we believe can be dismissed. In our patients there was no close association between mirror movements and intellectual ability or motor skill. Finally, we do not consider handedness to be relevant; two of our seven cases were sinistrals and the movements seen were no different in these patients.

We are grateful to Dr MFT Yealland, Dr KJ Zilkha, Professor WI McDonald and Professor CD Marsden for permission to publish details of patients under their care. We are also indebted to the Department of Clinical Neurophysiology for the somatosensory evoked potential studies.

\section{References}

1 Bauman GI. Absence of the cervical spine: Klippel-Feil syndrome. JAMA 1932; 98:129-32.

2 Erlenmeyer A. Die Schrift: Grundzüge ihrer Physiologie und Pathologie. Stuttgart: A Bonz, 1879.

3 Critchley M. Mirror-writing. London: Kegan Paul, Trench, Trubner \& Co, 1928.

4 Gesell A, Amatruda CS. Developmental Diagnosis: Normal and Abnormal Child Development, 2nd edition. New York: Paul B Hoeber 1947, Chapter 3:37; Chapter 11:190.

5 Schott GD, Wyke MA. Obligatory bimanual associated movements. J Neurol Sci 1977; 33: 301-12.

6 Lecky BRF, Murray NMF, Berry RJ. Transient radiation myelopathy: spinal somatosensory evoked responses following incidental cord exposure during radiotherapy. $J$ Neurol Neurosurg Psychiatry 1980; 43:747-50.

7 Harris AJ. Harris Tests of Lateral Dominance. New York: The Psychological Corporation, 1974.

8 Doll EA. (ed) The Oseretsky Tests of Motor Proficiency. Minnesota: American Guidance Service Inc, 1946. 
9 Wyke MA. Effect of brain lesions on the rapidity of arm movement. Neurology (Minneap) 1967; 17:1113-20.

10 Wyke MA. Influence of direction on the rapidity of bilateral arm movements. Neuropsychologia 1969; 7:189-94.

11 Ettlinger $G$, Blakemore $C B$, Milner AD, Wilson J. Agenesis of the corpus callosum: a behavioural investigation. Brain 1972; 95:327-46.

12 McGovern FH. The association of nerve deafness and retinitis pigmentosa. Ann Otol Rhinol Laryngol 1960; 69:1044-53.

13 Kloepfer HW, Laguaite JK, McLaurin JW. The hereditary syndrome of congenital deafness and retinitis pigmentosa (Usher's Syndrome). Laryngoscope 1966; 76:850-62.

14 Zülch KJ, Müller N. Associated movements in man. In: Vinken PJ, Bruyn GW (eds). Handbook of Clinical Neurology, Vol 1. Amsterdam: North Holland Publishing Co 1969, Ch 14:404-26.

15 Westphal C. Ueber einige Bewegungs-Erscheinungen an gelähmten Gliedern. Arch Psychiatr Nervenkr 1875; 5:803-34.

16 Woods BT, Teuber H-L. Mirror movements after childhood hemiparesis. Neurology (Minneap) 1978; 28:1152-8.

17 Walshe FMR. On certain tonic or postural reflexes in hemiplegia, with special reference to the so-called "associated movements". Brain 1923; 46:1-37.

18 Rimbaud L, Passouant P, Gros C, Pineau A. Gliome préfrontal chez un garçon de 17 ans, avec disjonction de la suture fronto-pariétale et syncinésies d'imitation. Sem Hop Paris 1948; 24: 761-3.

19 Jelasic F, Ott B. Kontralaterale Synkinesien. Deutsch Z Nervenheilk 1969; 195:187-98.

20 Sittig $O$. Ueber kontralaterale identische Mitbewegungen beim Schreiben. Monatsschr Psychiat u Neurol 1916; 39:286-93.

21 Stief A, Dancz M. Beiträge zur Pathologie der sogenannten symmetrischen Mitbewegungen. Deutsch $Z$ Nervenheilk 1934; 133:206-22.

22 Wilson SAK. Modern Problems in Neurology. London: Edward Arnold 1928, Ch 8:179-81.

23 Alexander L. Ueber symmetrische und gleichsinnige Mitbewegungen einer Extremität bei passiven Bewegungen und bei elektrische Reizung der anderen gleichnamigen (Symmetrische Mitbewegtwerden). J Psychol u Neurol 1932; 44:177252.

24 Fisher CM. Symmetrical mirror movements and left ideomotor apraxia. Trans Am Neurol Assoc $1963 ; 88: 214-6$.

25 Leavitt HC. Involuntary imitative movements of contralateral hand. J Nerv Ment Dis 1946; 103:514-7.

26 Burr CW, Crow CB. Mirror writing and other associated movements occurring without palsy. J Nerv Ment Dis 1913; 40:300-2.
27 Cernacek J. Contralateral motor irradiationcerebral dominance. Arch Neurol 1961; 4:165-72.

28 Green JB. An electromyographic study of mirror movements. Neurology (Minneap) 1967; 17:91-4.

29 Chaco J, Blank A. Mirror movements in hemiparesis. Confin Neurol 1974; 36:1-4.

30 Hopf HC, Schlegel HJ, Lowitzsch K. Irradiation of voluntary activity to the contralateral side in movements of normal subjects and patients with central motor disturbances. Europ Neurol 1974; 12:142-7.

31 Regli F, Filippa G, Wiesendanger M. Hereditary mirror movements. Arch Neurol 1967; 16:620-3.

32 Baird PA, Robinson GC, Buckler W St J. KlippelFeil syndrome: a study of mirror movement detected by electromyography. Amer J Dis Child 1967; 113:546-51.

33 Notermans SLH, Go KG, Boonstra S. EMG studies of associated movements in a patient with Klippel-Feil syndrome. Psychiat Neurol Neurochir 1970; 73:257-66.

34 Carmichael EA, Critchley M. Facial associated movements. J Neurol Psychopath 1924-25; 5: 124-32.

35 Mosberg WH. The Klippel-Feil syndrome. Etiology and treatment of neurologic signs. J Nerv Ment Dis 1953; 117:479-91.

36 Willard DP, Nicholson JT. The Klippel-Feil syndrome. Ann Surg 1934; 99:561-7.

37 Conrad B, Kriebel J, Hetzel WD. Hereditary bimanual synkinesis combined with hypogonadotropic hypogonadism and anosmia in four brothers. J Neurol 1978; 218:263-74.

38 Spillane JD, Pallis C, Jones AM. Developmental abnormalities in the region of the foramen magnum. Brain 1957; 80:11-48.

39 Gunderson $\mathrm{CH}$, Solitare GB. Mirror movements in patients with the Klippel-Feil syndrome. Arch Neurol 1968; 18:675-9.

40 Avery LW, Rentfro CC. The Klippel-Feil syndrome. Arch Neurol Psychiat 1936; 36:1068-76.

41 Gunderson $\mathrm{CH}$, Greenspan RH, Glaser GH, Lubs HA. The Klippel-Feil syndrome: genetic and clinical reevaluation of cervical fusion. Medicine (Baltimore) 1967; 46:491-510.

42 Bull JWD, Nixon WLB, Pratt RTC. The radiological criteria and familial occurrence of primary basilar impression. Brain 1955; 78:229-47.

43 Lindenberg R, Walker BA. Arnold-Chiari malformation in sibs. Birth Defects 1971; 7:234-6.

44 Van Wagenen WP, Herren RY. Surgical division of the commissural pathways in the corpus callosum. Arch Neurol Psychiat 1940; 44:740-59.

45 Freiman IS, Micheels L, Kahn RL. A hereditary syndrome characterised by mirror movements, left handedness and organic mental defect. Trans Am Neurol Assoc 1949; 74:224-6.

46 Parrish ML, Roessmann U, Levinsohn MW. Agenesis of the corpus callosum: a study of the frequency of associated malformations. $A n n$ Neurol 1979; 6:349-54. 
47 Fog E, Fog M. Cerebral inhibition examined by associated movements. In: MacKeith $\mathbf{R}, \mathbf{B a x} \mathbf{M}$ (eds). Minimal Cerebral Dysfunction: Little Club Clinics in Developmental Medicine, No 10. London: Heinemann 1963:52-7.

48 Abercrombie MLJ, Lindon RL, Tyson MC. Associated movements in normal and physically handicapped children. Dev Med Child Neurol $1964 ; 6: 573-80$.

49 Gordon $H$. Left-handedness and mirror writing especially among defective children. Brain 1921; 43:313-68.

50 von Fragstein. Ueber Synkinesien bei intaktem Nervensystem an der Hand eines selbst beobachteten Falles. Monatsschr Psychiat u Neurol 1901; 10:348-58.

51 Meyer BC. Report of a family exhibiting hereditary mirror movements and schizophrenia. J Nerv Ment Dis 1942; 96:138-52.

52 Friedman A, Levinson A. Mirror movements in a case of phenylpyruvic oligophrenia. J Pediatr $1954 ; 44: 553-7$.

53 Woods BT, Eby MD. Excessive mirror movements and impulsive aggression: two facets of the same deficit? (Abstract) Neurology (Minneap) 1978; 28:406.

54 Lackner E. Ueber zwei Fälle von Mitbewegungen bei intaktem Nervensystem. Arch Psychiatr Nervenkr 1917; 57:478-88.

55 Rasmussen $P$, Waldenström E. Hereditary mirror movements-a case report. Neuropaediatrie 1978; 9:189-94.

56 Lynn RB, Buchanan DC, Fenichel GM, Freemon FR. Agenesis of the corpus callosum. Arch Neurol 1980; 37:444-5.

57 Crutchfield CA. Gutmann L. Hereditary aspects of median-ulnar nerve communications. J Neurol Neurosurg Psychiatry 1980; 43:53-5.

¿q Thomayer J. O pohybech sdruženy̌ch. Sbornik Lékarský 1887; 5:48-60; see also Virchow-Hirsch, ref 59, for annotation in Germ`n.

59 Virchow-Hirsch. Nn: Virchow R, Hirsch A (eds). Jahresbericht über die Leistungen und Fortschritte in der gesammten Medicin. XXII Jahrgang. Bericht über das Jahr 1887, Part 1. Berlin: Hirschwald 1888:210.

60 Connolly K, Stratton P. Developmental changes in associated movements. Dev Med Child Neurol $1968 ; 10: 49-56$.

61 Foerster O. Die Mitbewegungen bei Gesunden, Nerven- und Geisteskranken. Jena: Fischer 1903.

62 Kristeva R, Keller E, Deecke L, Kornhuber HH. Cerebral potentials preceding unilateral and simultaneous bilateral finger movements. Electroencephalogr Clin Neurophysiol 1979; 47:229-38.

63 Schott GD. Some neurological observations on Leonardo da Vinci's handwriting. J Neurol Sci 1979; 42:321-9.

64 Schott GD. Mirror movements of the left arm following peripheral damage to the preferred right arm. J Neurol Neurosurg Psychiatry 1980; 43: 768-73.

65 Kornhuber HH. Cerebral Cortex, Cerebellum, and Basal Ganglia: an Introduction to their Motor Functions. In: Schmitt FO, Worden FG (eds). The Neurosciences Third Study Program. Cambridge, Mass: The MIT Press 1974, Ch 23:267-80.

66 Shibasaki H, Barrett G, Halliday E, Halliday AM. Components of the movement-related cortical potential and their scalp topography. Electroencephalogr Clin Neurophysiol 1980; 49:213-26.

67 Shibasaki H, Kato M. Movement-associated cortical potentials with unilateral and bilateral simultaneous hand movement. J Neurol 1975; 208:1919.

68 Roland PE, Larsen B, Lassen NA, Skinhøj E. Supplementary motor area and other cortical area in organization of voluntary movements in man. J Neurophysiol 1980; 43:128-36.

69 Merton PA, Morton HB. Stimulation of the cerebral cortex in the intact human subject. Nature 1980; 285:227.

70 Penfield W, Jasper H. Epilepsy and the Functional Anatomy of the Human Brain. London: Churchill 1954:66.

71 Drinkwater H. Obligatory bi-manual synergia with allocheiria in a boy otherwise normal. Transactions of the 17th International Congress of Medicine, London, 1913. Section XI-Neuropathology, Part II. London: Henry Frowde and Hodder \& Stoughton 1914:117-24.

72 Guttmann E, Maclay WS, Stokes AB. Persistent mirror-movements as a heredo-familial disorder. J Neurol Psychiatr (NS) 1939; 2:13-24.

73 Pratt RTC. The Genetics of Neurological Disorders. London: Oxford University Press 1967, Ch 12:130-1.

74 Shibasaki H, Barrett G, Halliday E, Halliday AM. Cortical potentials following voluntary and passive finger movements. Electroencephalogr Clin Neurophysiol 1980; 50:201-13.

75 Crawford C. Report of a family showing "mirror" movements. Australas Ann Med 1960; 9:176-9.

76 Haerer AF, Currier RD. Mirror movements. Neurology (Minneap) 1966; 16:757-60 and 765 .

77 Nathan PW, Smith MC. Long descending tracts in man. Brain 1955; 78:248-303.

78 Nathan PW, Smith MC. Effects of two unilateral cordotomies on the motility of the lower limbs. Brain 1973; 96:471-94.

79 Lawrence DG, Kuypers HGJM. The functional organization of the motor system in the monkey. I. The effects of bilateral pyramidal lesions. Brain 1968; 91:1-14.

80 Lawrence DG, Kuypers HGJM. The functional organization of the motor system in the monkey. II. The effects of lesions of the descending brainstem pathways. Brain 1968; 91:15-36.

81 Lawrence DG, Hopkins DA. The development of motor control in the rhesus monkey: evidence 
concerning the role of corticomotoneuronal connections. Brain 1976; 99:235-54.

82 Van der Staak C. Intra- and interhemispheric visual-motor control of human arm movements. Neuropsychologia 1975; 13:439-48.

83 Jung $R$, Dietz V. Verzögerter Start der Willkürbewegung bei Pyramidenläsionen des Menschen. Arch Psychiatr Nervenkr 1975; 221:87-109.

84 Phillips CG, Porter R. Corticospinal Neurones: Their Role in Movement. New York and London:
Academic Press 1977:319.

85 Swaan D, Van Wieringen PCW, Fokkema SD. Auditory electromyographic feedback therapy to inhibit undesired motor activity. Arch Phys Med Rehabil 1974; 55:251-4.

86 Somers AB, Levin HS, Hannay HJ. A neuropsychological study of a family with hereditary mirror movements. Dev Med Child Neurol 1976; 18:791-8. 